\title{
Notification List Notification that new names and new combinations
have appeared in volume 57, part 10, of the IJSEM
}

Correspondence

Jean Euzéby

email address can be found at

www.bacterio.net
This listing of names published in a previous issue of the IJSEM is provided as a service to bacteriology to assist in the recognition of new names and new combinations. This procedure was proposed by the Judicial Commission [Minute 11(ii), Int J Syst Bacterio/ 41 (1991), p. 185]. The names given herein are listed according to the Rules of priority (i.e. page number and order of valid publication of names in the original articles). Taxonomic opinions included in this List (i.e. the creation of synonyms or the emendation of circumscriptions) cannot be considered as validly published nor, in any other way, approved by the International Committee on Systematics of Prokaryotes and its Judicial Commission.

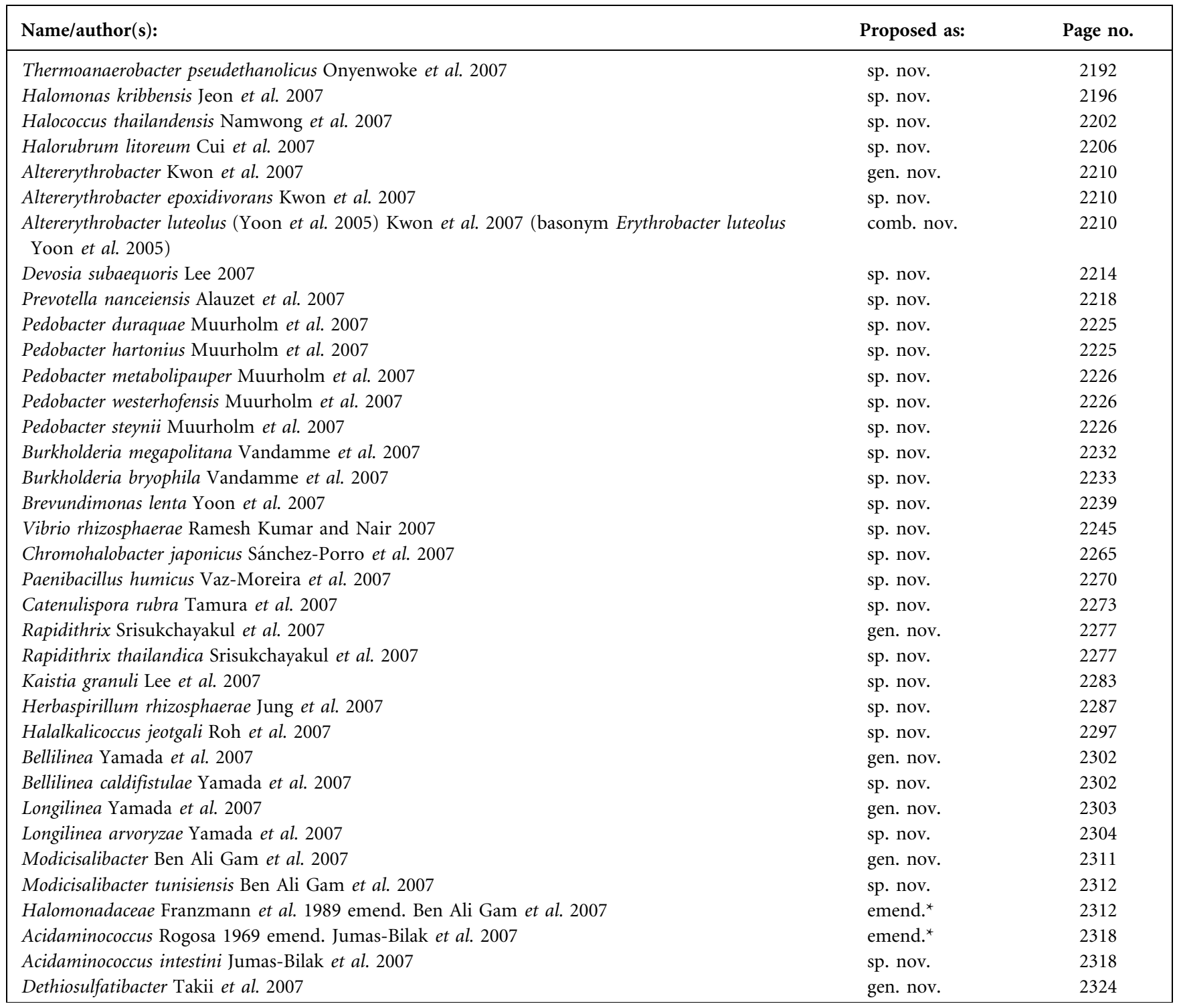


cont.

\begin{tabular}{|c|c|c|}
\hline Name/author(s): & Proposed as: & Page no. \\
\hline Dethiosulfatibacter aminovorans Takii et al. 2007 & sp. nov. & 2324 \\
\hline Salinicoccus kunmingensis Chen et al. 2007 & sp. nov. & 2330 \\
\hline Fervidobacterium changbaicum Cai et al. 2007 & sp. nov. & 2335 \\
\hline Rubritalea spongiae Yoon et al. 2007 & sp. nov. & 2339 \\
\hline Rubritalea tangerina Yoon et al. 2007 & sp. nov. & 2340 \\
\hline Chryseobacterium haifense Hantsis-Zacharov and Halpern 2007 & sp. nov. & 2347 \\
\hline Mucilaginibacter Pankratov et al. 2007 & gen. nov. & 2352 \\
\hline Mucilaginibacter paludis Pankratov et al. 2007 & sp. nov. & 2352 \\
\hline Mucilaginibacter gracilis Pankratov et al. 2007 & sp. nov. & 2353 \\
\hline Microbacterium sediminicola Kageyama et al. 2007 & sp. nov. & 2357 \\
\hline Microbacterium marinilacus Kageyama et al. 2007 & sp. nov. & 2358 \\
\hline Desulfothermus okinawensis Nunoura et al. 2007 & sp. nov. & 2363 \\
\hline Microbulbifer celer Yoon et al. 2007 & sp. nov. & 2366 \\
\hline Reinekea blandensis Pinhassi et al. 2007 & sp. nov. & 2374 \\
\hline Rheinheimera Brettar et al. 2002 emend. Merchant et al. 2007 & emend.* & 2379 \\
\hline Rheinheimera texasensis Merchant et al. 2007 & sp. nov. & 2379 \\
\hline Salsuginibacillus Carrasco et al. 2007 & gen. nov. & 2384 \\
\hline Salsuginibacillus kocurii Carrasco et al. 2007 & sp. nov. & 2384 \\
\hline Anderseniella Brettar et al. 2007 & gen. nov. & 2403 \\
\hline Anderseniella baltica Brettar et al. 2007 & sp. nov. & 2404 \\
\hline Salimicrobium Yoon et al. 2007 & gen. nov. & 2409 \\
\hline Salimicrobium album (Hao et al. 1985) Yoon et al. 2007 (basonym Marinococcus albus Hao et al. 1985) & comb. nov. & 2409 \\
\hline $\begin{array}{l}\text { Salimicrobium halophilum (Ventosa et al. 1990) Yoon et al. } 2007 \text { (basonym Bacillus halophilus Ventosa } \\
\text { et al. 1990) }\end{array}$ & comb. nov. & 2409 \\
\hline Salimicrobium luteum Yoon et al. 2007 & sp. nov. & 2409 \\
\hline
\end{tabular}

${ }^{*}$ Taxonomic opinion. 